\title{
Quantifying the Effects of the Inclusion and Segregation of Contracts for Difference in Australian Equity Markets
}

\author{
Shaen Corbet \\ DCU Business School (DCUBS), \\ Dublin City University (DCU), Dublin 9, Ireland. \\ Tel:+3531700 5993. Email: shaen.corbet@dcu.ie \\ Cian Twomey \\ J.E. Cairnes School of Business and Economics, \\ National University of Ireland, Galway (NUIG), Ireland. \\ Tel: +353 9149 3121. Email: cian.twomey@nuigalway.ie
}

\begin{abstract}
This study examines the effects that Contracts for Difference (CFDs) have had on the Australian equity market, either as an accelerant for mispricing, or as a source of increased market functionality through the addition of a new tradable product and increased liquidity. The Australian Securities Exchange (ASX) made the decision to segregate CFDs to a separate ring-fenced exchange in November 2007. This study uses EGARCH techniques to test for the effects of CFDs on return volatility at the time of CFD inclusion and segregation in Australian equity markets at the index and equity-specific level. A fully worked explanation and example of a CFD-influenced 'overhang' is also provided. The results provide evidence that cannot reject the presence of 'overhangs' in Australian equity markets.
\end{abstract}

Keywords: Contracts for Difference; EGARCH; equity markets; volatility. JEL Classifications: G12; G15

\section{Introduction}

The Contract for Difference (CFD) industry has grown significantly since the product's creation in the mid-1990s. The market for CFDs grew rapidly after their inception in worldwide exchanges, up to the period before the recent international crises. Investors can use CFDs to open positions either long or short with a standard rate of margin of ten per cent. Therefore the position could be theoretically ten times larger than the amount of capital the investor initially possessed. The combined movements of CFD investors and the hedging practices of CFD providers could potentially affect the behaviour of equity market volatility in Australia. CFDs may have also had a beneficial impact on Australian markets through the addition of new liquidity provided by the product's leverage.

This research offers a novel perspective on the role that CFDs have had on international equity markets. An Exponential Generalised Autoregressive Conditional Heteroskedasticity (EGARCH) methodology is used at both the index and equity specific level to investigate volatility differences in the period before their arrival in 2002 and thereafter. A total number of 3,085 daily Australian equity market observations between 1998 and 2011 were used in the study. CFDs by their very nature are a leveraged, short-term investment product, with all the characteristics to attract day-trading speculative investment, which has been shown to increase market volatility. This was initially uncovered by Edwards (1988) and Baillie and Bollerslev (1991), with more recent evidence uncovered by Chung et al. (2009) and Schwert (2011). Previous research on CFDs focuses specifically on contract design (Brown et al., 2009). This research is among the first to explicitly investigate the direct market impacts of CFDs.

Corbet and Twomey (2013) found significant volatility reductions in Irish equity markets after the introduction of CFDs. This was explained through the findings of the Report of the Irish Banking Commission (2011) into the systemic collapse of the Irish banking system. This report uncovered 
significant 'overhangs' stemming from CFD trading that was found to be capable of influencing equity market volatility. An 'overhang' develops when significant volumes are placed within a few ticks of the currently traded bid and ask price. 'Overhangs' are explained in detail with a fully worked example in section three. This paper attempts to investigate whether 'overhangs' are present in Australian equity markets, which itself provides a unique structural exchange transformation. CFDs were introduced in Australia in 2002, similar to numerous other international exchanges. But in November 2007, CFDs were subsequently segregated to a separate ASX CFD exchange. This change was undertaken in an attempt to increase market transparency. Supporters of the decision to ring-fence CFDs argue that it has withdrawn most pure speculative trading from the exchange, which may reduce the volatility of the market as a whole (FSA, 2007).

We must remember that CFDs are not an appropriate long-term investment vehicle due to the commissions and overnight interest charges attached for the use of leverage. Therefore, CFDs are suited to more short-term, speculative investment, referred to as noise trading, which is associated with increased market volatility (Brown, 1999, Bloomfield et al., 2009). If 'overhangs' are present on the Australian equity market, volatility changes would be present at the time that CFDs were introduced and again at the time of segregation. Research based on CFDs is becoming more important as increases in their trading volumes indicate strong growth as a trading product. There has also been more evidence coming to light of potential detrimental equity market anomalies stemming from their presence (FSA, 2007, Report of the Irish Banking Commission, 2011). The EGARCH methodologies used in this research can shed light on volatility changes stemming from the presence of CFDs in Australian equity markets.

From a policy perspective, it is vital to understand if CFDs have had a volatility impact upon Australian equity markets. If it is the case that CFDs are found to have directly influenced volatility, it may be necessary for the exchange and financial regulators to implement regulatory changes to mitigate any potential effects. For example, if it is found that CFDs are negatively impacting market functionality, then further policy response will have to focus on tax changes to reduce the appeal to use CFDs for high frequency trading, margin limits to reduce position sizes or indeed, holding limits to reduce position accumulation through leverage.

The rest of this paper is structured as follows: In the next section we define Contracts for Difference and the previous literature on volatility relevant to this paper. In Section III, we discuss the development of bid and ask price 'overhangs' recently uncovered in Irish equity markets. Section IV introduces the research methodology used. Section V follows with an overview of the results uncovered from the EGARCH models used. Finally, in Section VI, we conclude.

\section{Contracts for Difference and Previous Literature on Volatility}

CFDs are structured towards those investors seeking additional levels of higher risk investments in their portfolios. Due to the leveraged nature of CFDs, market movements amplify the investor's gains and losses in multiples of the provided level of margin. In Australia, CFDs are usually structured to allow an investor to obtain ten per cent margin, while borrowing the remaining ninety per cent of the investment from their CFD broker. This enables the investor to enhance their buying power tenfold. When CFDs are used to invest, a price increase of ten per cent results in one hundred per cent profits, whereas a ten per cent fall in price leaves the investor at a total $\operatorname{loss}^{1}$. When this scenario unfolds, the investor must meet margin calls to maintain the position. Failure to do so results in the position being immediately closed. CFDs therefore act as an extremely cheap, non-selective source of investment finance due to the relative ease of account establishment.

CFDs by their very nature thrive in periods of short term extreme volatility, as investors increase their use of leverage to maximise the amount of a particular equity that they can afford. Financial crises can therefore generate a thriving environment in which CFDs can trade. Longer horizon investors would refrain from using CFDs due to the commissions and overnight interest charges that must be paid for the use of borrowed margin to create leverage. It must also be noted that CFDs are not a common feature across all financial markets. The United States for example has not

\footnotetext{
${ }^{1}$ When the investor has opened a 'short' position, a price fall of ten per cent (assuming ten per cent margin) results in one hundred per cent profits, whereas a price increase of ten per cent leaves the investor at a total loss.
} 
allowed CFDs to be traded as a result of restrictions ${ }^{2}$ on OTC financial instruments ${ }^{3}$ implemented by the Securities and Exchange Commission (SEC). Therefore, CFDs on US equities are only available to non-US citizens.

CFDs were originally developed by Smith New Court plc. in the early 1990s, who found purpose for their use as a method of shorting financial markets using high leverage, low margin and tax free investment. They were subsequently bought by Merrill Lynch in 1995 for $£ 526$ million. CFDs were institutionally traded until 1998, when they became publically available. In 2002, CFDs were first available on equities present on the Australian Stock Exchange (ASX). Trading estimates in the United Kingdom in 2007 were produced by the Financial Services Authority (FSA), who found that 'the CFD market in the UK has grown significantly in the last five years. International estimates suggest that about thirty per cent of equity trades were in some way driven by CFD transactions' (FSA-CP07-20, 2007). Estimates of the proportion of CFDs traded in comparison to fully margined equity in Australian ranged from 10 to 60 per cent in the period between 2002 and 2007. This wide and un-accurate variety of estimates, directly represent the lack of transparency available on the product, presenting a case against CFDs due to significant information deficiencies. This paper provides an accurate estimate of the proportion of CFD trading that took place directly after segregation in 2007, up to the beginning of 2010.

In Ireland and the United Kingdom, CFD licences fall under betting and gambling legislation, therefore all profits are tax free. These tax exemptions stemmed from government incentives to attempt to grow the bloodstock industry. This tax free characteristic is an attractive trait to investors in Ireland and the United Kingdom, who otherwise would have to pay capital gains tax on fully margined equity investments. This has been identified as one of the key characteristics driving the growth of CFDs in these countries. In Australia, the tax system in relation to CFDs is more rigorous. CFDs fall under the scope of income tax law, which is designed to be strictest in situations where traders are identified as day-traders or high frequency traders. CFD profits are subject to standard taxation, but tax rates are significantly reduced if a CFD trader can show that they are using the investment product to hedge an alternative position, or indeed are entering the position in a manner not synonymous with the short time-frames of day traders (Deloitte, 2010). If an investor can prove that they are investing in CFDs as a business venture (or out of business necessity), simple tax laws are used such as those when calculating tax liabilities against ordinary income. Losses in this situation are deductible against other taxable income, with the caveat that this process cannot continue year on year. It is also possible to write off the costs of trading against these same tax liabilities, along with specific costs of trading, including equipment and training. Otherwise, if the CFD investor cannot segregate themselves from the assumption that they are opening the position in a manner to speculate or trade at a high frequency level, they will be subjected to a higher rate of taxation on their profits.

A lack of transparency has been identified as one of the key issues associated with CFDs. The transparency of CFDs in Australia was brought into question by regulators prior to 2007 (FSA, 2007). Rather than continue to operate under unknown parameters, the decision was made by the Australian Securities Exchange to segregate CFDs to provide a more transparent mechanism and platform from which they could be easily monitored. Therefore, on November $5^{\text {th }} 2007$, CFDs became exchange traded in Australia. Investors could for the first time observe a CFD exchange separated from the standard equity market, but still trade with the same leverage as before. The ASX was responsible for maintaining a fair and orderly ASX CFD exchange. Counterparty risk was also minimised as the settlements of all obligations were guaranteed by the SFECC ${ }^{4}$.

\footnotetext{
${ }^{2}$ Regulation T (12 CFR $\$ 220$ - Code of Federal Regulations) governs the extension of credit by securities brokers and dealers in the United States. It is best known as a control function of margin requirements for stocks bought through leveraged products. The initial margin requirement for equities in the United States is 50 per cent and has been so since 1974. Regulation T gives the Federal Reserve the right to change the initial margin requirements at any time it chooses to do so.

${ }^{3}$ Over the counter (OTC) refers to trading that occurs between two parties without any exchange supervision.

${ }^{4}$ SFE Clearing Corporation (SFECC) is an Australian company operating all clearing and settlement facilities in Australian equity markets.
} 
There have been numerous international instances of trading irregularities associated with CFD investment. In Germany, a report by the European Security Markets Expert Group (ESME) in 2009, found that a large unwinding by Porsche of options related to CFDs in Volkswagen (VW), combined with takeover rumours, had triggered and fuelled a five hundred per cent price increase in less than seven days in late October 2008. These irregularities have attracted increased investigation into CFDs as a tradable product. In 2011, The Central Bank of Ireland raised concerns about the Irish CFD industry, specifically that there was a serious deficiency in transparency and a lack of information gathered by CFD brokers (Central Bank of Ireland, 2011). CFD brokers' clients were also found to have been accepted with 'inadequate assessment of appropriateness' under MiFID regulations ${ }^{5}$. Risk disclosures supplied by CFD brokers were found to be inadequate and 'in some cases' misleading.

CFDs have also been associated with a market anomaly called an 'overhang' on the bid and ask prices of the equities for which CFDs are available. 'Overhangs' are created when large CFD positions are created and are then hedged using standard stop losses and limit orders to protect the CFD provider. These 'overhangs' are found to restrict market functionality and hinder trading, thus reducing volatility. This paper aims to determine whether this scenario is consistent with recent behaviour in Australian equity markets. The Report of the Irish Banking Commission (2011) to investigate the systemic banking crisis in Ireland found that an 'overhang' existed from large CFD trades that were capable of leading to confusion and differing interpretations of what was driving the share price collapse of Anglo Irish Bank ${ }^{6}$. These findings have motivated this paper to investigate whether 'overhangs' were more discernible in Australian markets (particularly after their inception and subsequent segregation) and indeed whether they were associated with other systemic issues.

An 'overhang' develops when significant volumes are placed within a few ticks of the currently traded bid and ask price. CFD brokers would have used stop losses and limit orders to protect themselves from losses stemming from clients running out of margin. The implementation of these large leveraged orders would have taken a significantly large amount of fully-margined investment to reduce, or alternatively, a CFD position opened in the other direction. Without either of these events occurring, the average volumes traded would not have been large enough to dissolve the 'overhang', therefore the price can become range-bound. Leveraged products have been longassociated with increased exchange volatility, but CFD-initiated 'overhangs' may also influence volatility. A specific example of an 'overhang' is discussed in detail in section III.

To date, there is no research based on volatility changes after the inclusion of CFDs as a trading product in Australia. There is literature based on CFDs in commodity and currency markets (eg. Brown et al., 2009), but the methodology and results act only as an explanation of the regulatory restrictions imposed by the Australian Securities Exchange (ASX) to mitigate the potential effects of CFDs. However, a significant amount of research on other derivatives markets directly supports this study's investigation. Primarily, these papers find that derivatives trading as a whole increased market volatility. Some authors believe that destabilising effects associated with derivatives trading is present in financial markets as the product is used mostly by uninformed investors (Bessembinder and Seguin (1992), Antoniou and Holmes (1995), Gulen and Mayhew (2000)). Pok and Poshakwale (2004) found equity futures market volatility increases, but noted greater sensitivity of spot market prices to new information and efficiency improvements through faster transfer of information. These papers also hypothesise that the lack of trading margin directly increases market risk and volatility, as most agents leverage their available funds.

\footnotetext{
${ }^{5}$ Market in Financial Instruments Directive (MiFID) applied to investment banks, portfolio managers, brokers, corporate finance firms and some derivative and commodity related firms. MiFID represents the next step into fully integrating the European Union's financial markets.

${ }^{6}$ The scenario the Report of the Irish Banking Commission (2011) refers to is based on a position in Anglo Irish Bank allegedly accumulated by an Irish businessman in 2007. In January 2007, this individual purchased five per cent of the bank's value, and continued to accumulate positions until September 2007, where the position held was approximately twenty-four per cent of the company's value. It is widely reported that rather than selling the position and significantly reduce the bank's share price, a side-deal comprising of Anglo Irish Bank loans to purchase its own equity took place. The transfer of this position and the stop losses on a position worth twenty four per cent of the bank at peak would have been significant and certainly strong enough to hinder market functionality at this sensitive time.
} 
Another branch of research argues that derivatives trading reduces spot market volatility and in fact stabilises the market. In this sense, derivatives are found to be an efficient medium of price discovery. Other benefits include improved market depth, a reduction in market asymmetries and less cash market volatility as found by Kumar et al. (1995) and Antoniou et al. (1998). Other research supporting volatility reductions after investigating derivative products include Chathrath et al. (2003) and Drimbetas et al. (2007). Bologna and Cavallo (2002) investigate the impact of the introduction of futures trading on the underlying asset volatility on the Italian Stock Exchange through the use of an EGARCH $(1,1)$ methodology. Their results found that the introduction of Italian stock futures trading led to reduced stock market volatility and no other factor was found to have systematically reduced it. This effect is also found to have been immediate. The author's findings are consistent with theories stating that active and developed futures markets enhance the efficiency of the corresponding spot markets.

In this paper, we implement an EGARCH methodology on the ASX Index and thirty five individual Australian equities between January 1998 and December 2011. This time period incorporates the inception of CFDs in 2002 and their subsequent ring-fencing in 2007. The FTSE 100 and Nikkei 225 are used in the EGARCH models to mitigate international effects at the index level. A dummy variable is used to denote the period where CFDs are present in Australian equity markets. Results are then inferred. Also, we explain the dynamics of the 'overhang' and how the results found in this paper indicate their presence.

\section{How Has The 'Overhang' Affected Australian Equity Market Volatility?}

This research attempts to investigate whether the 'range-bound' effects associated with 'overhangs' can be found at the index and equity-specific level in Australia given the special treatment offered to CFDs through their ring-fencing in 2007. The starting point to this analysis is to provide a clear understanding of the creation and potential influences of 'overhangs' on equity markets. CFDs are traded in the same manner as any standard equity. They can be purchased long or short, with market orders such as stop losses and limit orders available at the investor's request. The main difference is the provision of leverage by the CFD provider. The standard rate of margin is ten per cent, which enables an investor to theoretically afford ten times more equity than they could have if they had not used CFDs. The caveat is that if the share price falls ten per cent (if the investor is long), the investor is now illiquid and must meet margin calls ${ }^{7}$ to maintain the position. If the investor does not meet margin requirements, the position is immediately closed. The alternative is that the price of the equity increases ten per cent, which doubles the investor's initial capital. Therefore, CFDs amplify the gains and losses of standard equity trading. Two important issues associated with CFDs are the decision-making processes of traders using the investment product and their investment horizons. If CFDs were used as a long-term investment vehicle, there would be additional returns sought due to the commissions and interest charges associated with holding the position overnight. Thus buy and hold investors would not view CFDs as a feasible investment mechanism. Short term speculative investors would be the most likely to use CFDs.

Table 1. Level II trading data example with no CFD transactions

\begin{tabular}{|c|c|c|c|c|c|}
\hline \multicolumn{7}{|c|}{ ABCD plc. 0.12 (-2.50\%) 13.01 Vol: $2,400,575$} \\
\hline Buy Orders & (Volume) & Price to buy & Price to sell & (Volume) & Sell Orders \\
\hline $\mathbf{1 3 . 0 1}(\mathbf{1})$ & $\mathbf{8 0 , 0 0 0}$ & $\mathbf{0 . 1 1 5}$ & $\mathbf{0 . 1 2 5}$ & $\mathbf{9 0 , 0 0 0}$ & $\mathbf{1 3 . 0 1}(\mathbf{3})$ \\
\hline $13.01(3)$ & 50,000 & 0.110 & 0.130 & 30,000 & $13.01(5)$ \\
\hline $13.00(4)$ & 150,000 & 0.100 & 0.140 & 40,000 & $13.01(1)$ \\
\hline $13.00(2)$ & 90,000 & 0.090 & 0.150 & 10,000 & $13.01(2)$ \\
\hline $13.00(4)$ & 250,000 & 0.080 & 0.160 & 5,000 & $13.01(4)$ \\
\hline $13.01(1)$ & 175,000 & 0.070 & 0.170 & 15,000 & $13.01(4)$ \\
\hline
\end{tabular}

Note: The above table represents an example of the level II data that a trader would view for ABCD plc. in a situation without CFD hedging through stop-losses and limit orders present in the market. The left and right hand columns represent the time and trader number that implemented the order to buy or sell the stock.

\footnotetext{
${ }^{7}$ You would receive a margin call from a broker if one or more of the assets held in your leveraged portfolio decreases in value below a certain point. You would be forced either to deposit more money in the account or to sell off some of your assets. Otherwise, you would be required to close the position if the margin call is not met.
} 
But how can the introduction of CFDs reduce volatility? CFDs have also been associated with a market anomaly called an 'overhang' on the bid and ask prices of the equities for which CFDs are available. This anomaly was first associated with CFDs in a report sanctioned by the Irish Banking Commission (2011) investigating the collapse of Anglo Irish Bank. These 'overhangs' are found to restrict market functionality and hinder trading, thus reducing volatility. The Report of the Irish Banking Commission (2011) to investigate the systemic banking crisis in Ireland found that an 'overhang' existed from large CFD trades that were capable of leading to confusion and differing interpretations of what was driving the share price collapse of Anglo Irish Bank. Corbet and Twomey (2013) found significant decreases in volatility in Irish equities after the introduction of CFDs in Ireland, thus endorsing the proposition of 'overhangs' being present in Irish equity markets. We can provide a simple example of an 'overhang' by investigating level II data before and after the implementation of a standard market order. We will focus on ABCD plc. as an example. If the price of a share in $\mathrm{ABCD}$ plc. is $\mathrm{A} \$ 0.12$ at $1 \mathrm{pm}$, a trader would view the hypothetical level II situation in table one.

If for example, a CFD trader has bought $\mathrm{A} \$ 2$ million of $\mathrm{ABCD}$ equity at $\mathrm{A} \$ 0.12$ using ten per cent margin, and we assume his/her net wealth is A \$5 million (A \$2 million invested in CFDs and A $\$ 3$ million held in a margin account with the CFD broker), this means a twenty-five per cent fall in share price results in a total loss for the CFD trader. The CFD broker inputs a limit-order to sell shares at $1.03 \mathrm{pm}$ to protect against the price 'gapping' their required minimum threshold. The scale of this position becomes evident in table two. The $\mathrm{A} \$ 2$ million CFD investment at $\mathrm{A} \$ 0.12$ is the equivalent size of a A $\$ 20$ million fully margined investment $(166,666,667$ shares at $A \$ 0.09)$. If the price falls to $\mathrm{A} \$ 0.09$, the trader has lost his entire available margin, thus to protect the company, the broker will leave an order to sell the shares at $\mathrm{A} \$ 0.09$. Other market agents, unaware of what is transpiring in this brokerage will see the level II data change to that found in table two.

The other traders in the market can now see the extremely large volumes at $\mathrm{A} \$ 0.09$ and view this as a large 'sell signal'. But if the same scenario was to occur when a trader opened a short position, a similar limit order would be placed $\mathrm{A} \$ 0.15$. This would create an exceptionally large level of volume to be traded at $\mathrm{A} \$ 0.09$ and $\mathrm{A} \$ 0.15$, creating an 'overhang' which effectively traps the volatility of the market within this trading range until an equally large trader enters the market with enough financial capital to remove these orders. Until this occurs, the volatility of the exchange would fall as the normal mechanics of daily trading are affected. If we assume that all investors are rational and maximise all investible funds and it is assumed that they invested using CFDs, their stop losses would be found at the point where they run out of trading margin. Therefore, every CFD trade would be accompanied by an associated stop loss or limit order that would exacerbate an 'overhang'. These effects would be more pronounced in markets with smaller average trading volumes.

Table 2. Level II trading data example with CFD broker hedging implemented

\begin{tabular}{|c|c|c|c|c|c|}
\hline \multicolumn{7}{|c|}{ ABCD plc. 0.12 (-2.50\%) } & 13.05 Vol: $2,400,575$ & (Volume) & \multicolumn{1}{c|}{ Sell Orders } \\
\hline Buy Orders & (Volume) & Price to buy & Price to sell & $\mathbf{9 0 , 0 0 0}$ & $\mathbf{1 3 . 0 5}(\mathbf{3})$ \\
\hline $\mathbf{1 3 . 0 5}(\mathbf{1})$ & $\mathbf{8 0 , 0 0 0}$ & $\mathbf{0 . 1 1 5}$ & $\mathbf{0 . 1 2 5}$ & 30,000 & $13.05(5)$ \\
\hline $13.05(3)$ & 50,000 & 0.110 & 0.130 & 40,000 & $13.01(1)$ \\
\hline $13.00(4)$ & 150,000 & 0.100 & 0.140 & 10,000 & $13.01(2)$ \\
\hline $13.05(2)$ & $\mathbf{1 6 6 , 7 5 6 , 6 6 7}$ & 0.090 & 0.150 & 5,000 & $13.01(4)$ \\
\hline $13.00(4)$ & 250,000 & 0.080 & 0.160 & 15,000 & $13.01(4)$ \\
\hline $13.01(1)$ & 175,000 & 0.070 & 0.170 & 170 \\
\hline
\end{tabular}

Note: The above table represents an example of the level II data that a trader would view for ABCD plc. after the implementation of a stop-loss order to hedge the CFD broker's counterparty risk of an investor's A $\$ 2$ million investment through CFDs. The order of 166,666,667 shares at A $\$ 0.09$ represents a full hedge against the $A \$ 2$ million position opened at $A \$ 0.12$ (The new value of $166.756,667$ shares at $A \$ 0.09$ is the combination of the CFD position of 166,666,667 shares and the existing 90,000 shares present before the CFD order was implemented). This also creates a significant 'overhang' on the bid-side of the market which is clearly evident from the scale of the position in comparison to other traders in the market on both the bid and ask side of the market. The left and right hand columns represent the time and trader number that implemented the order to buy or sell the stock. 

Markets

If there is a high level of CFD trading within the exchange, there would be a reduced probability of an 'overhang' been present in the market. This is due to the fact that CFD traders would hold sufficiently large positions to absorb large market orders. The alternative appears to have occurred in Irish equity markets, where there is not enough CFD trading in the exchange to absorb large market orders. This research attempts to investigate whether these findings are present on Australian equity markets.

Figure 1. The impact of CFD volumes on the bid and ask price

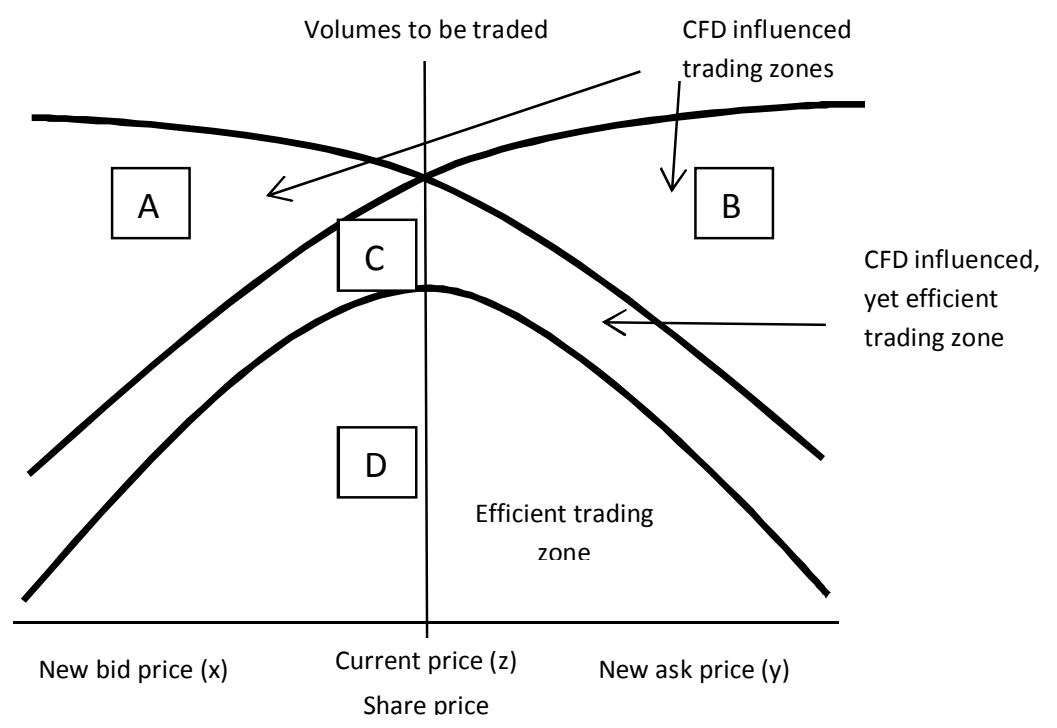

Note: The above figure represents the theoretical situation when CFD volumes are placed in an exchange to be bought or sold by the market

Figure 2. CFD trading and probability of overhangs in the Australian stock exchange

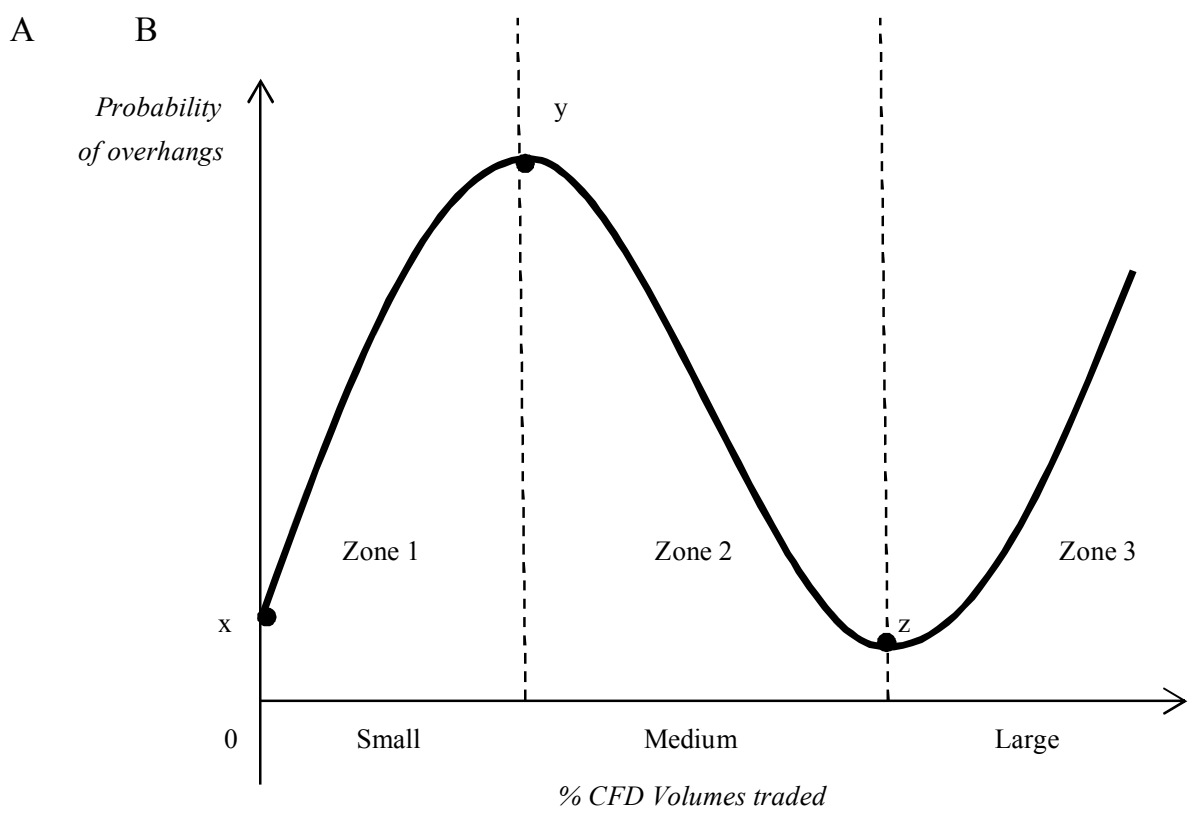

Note: The above figure represents the relationship between the percentage of volumes on the Australian Stock Exchange that are CFD traded and the probability of the presence of an overhang. At point $x$, there is no CFD trading available in the market, thus volumes traded are fully margined. Therefore in zone 1, there are a small number of CFD traders in the market, but as this number grows larger in proportion to fully margined traders, the potential for overhangs to be present increases. In zone 2, there are a sufficient number of CFD traders to 
trade with each other, therefore the probability of an overhang falls. The increased potential for overhangs also occur in zone 3 where extremely large CFD traders can dominate the market.

In figure 1, When a CFD provider implements a stop loss or limit order to hedge a CFD provider against the counterparty risk of holding client positions, areas A and B represent the large volumes now in the market, creating situations where 'overhangs' develop. These areas are zones where market volatility fall due to restrictive trading conditions. Zone $\mathrm{C}$ is the intersection of both 'overhang' influenced trading regions, where there is an appropriate amount of CFD trading on both the buy and sell side of the market, therefore the probability of market volatility effects stemming from CFDs are reduced. We can see that area D is the trading zone with no CFDs present, therefore the reduction of leverage reduces the average trade size in the market, thus reducing the probability of an 'overhang' being present.

In figure 2, there is a trading zone (area 2) where the fully margined market is unable to efficiently absorb the amount of CFD trading within the market. When there is a small amount of CFD trading in the market (left of line A), the percentage of CFD trading is too small to have any effect, thus fully margined investors dominate, and to the right of line $\mathrm{B}$, there is a sufficient number of CFD traders to absorb the volumes traded. With the availability of data based on the exact percentages of CFD traders per day, it would be possible to calculate these areas and input thresholds of CFD trading to counteract any market hindering effects that CFDs possess.

\section{Research Methodology}

The primary research question is: "how have CFDs affected Australian equity market volatility?' The ASX exchange has provided a dataset to investigate the inclusion and segregation of CFDs from the primary ASX exchange. This has enabled the calculation of the proportion of CFDs traded throughout fifty equities on the ASX CFD exchange and the overall ASX exchange. To investigate volatility changes in the period before and after the introduction and withdrawal of CFDs, Exponential GARCH (EGARCH) techniques are applied. The period of investigation is based between the first quarter of 1999 and the fourth quarter of 2011. CFD-specific data is available between the fourth quarter, 2007 and the first quarter of 2010. To estimate the volumes of CFDs traded, data is taken from the ASX CFD exchange. The individual volume data is de-leveraged to the value of fully margined equity that would have been purchased to equal the position. This resulting dataset is then matched against standard equity on the ASX exchange to calculate the proportion of CFD trading that occurred.

To calculate volatility changes before and after the introduction of CFDs, we first calculate daily return as $R_{t}=\frac{P_{t}-P_{t-1}}{P_{t-1}}$. Dividends in this model are ignored for simplicity. The EGARCH model uses a dummy variable to signal both the inclusion and the division of the ASX CFD exchange, denoted as zero without CFDs and one otherwise. Results are inferred from the coefficient of the dummy term. At the equity-specific level, at the time of implementation of CFDs (2002), Australian equities did not have sufficient liquidity to infer sufficiently accurate results in the EGARCH methodology. The fifty equities available at the time of CFD segregation did have sufficient liquidity in 2007, thus significant volatility estimates are obtained.

The EGARCH model was developed by Nelson (1991). The ARCH (p) and GARCH (p,q) models impose symmetry on the conditional variance structure and the logarithmic construction of the conditional variance equation ensures that the estimated conditional variance is strictly positive, thus the non-negativity constraints used in the estimation of ARCH and GARCH models are not necessary. To mitigate international effects such as shocks and crises, other exchanges can be added to the mean equation, resulting in the $\gamma$ coefficient of the dummy variable $D_{C F D}$, being explicitly related to the exchange being investigated. This withdraws 'international effects'. For example, in the ASX investigation, the Nikkei 225 and FTSE 100 were included as they were statistically significant at the $1 \%$ level ${ }^{8}$.

\footnotetext{
${ }^{8}$ After thorough analysis of the correlations and mean spillovers between all major international exchanges and the ASX, the Nikkei 225 and the FTSE 100 were deemed to offer the most significant explanatory benefits to the EGARCH models of Australian equities at both the index and equity-specific level. The inclusion of these exchanges in the mean equation of the $\operatorname{EGARCH}(1,1)$ models incorporates international effects into the
} 
After completing the standard robustness tests ${ }^{9}$, the EGARCH $(1,1)$ methodology was selected as the appropriate model to test for volatility changes after CFD introduction. The EGARCH model used to investigate the inception and segregation of CFDs at the index level is represented as:

$$
\begin{gathered}
R_{t}=b_{0}+b_{1} R_{t-1}+b_{2} R_{\text {Nikkei }_{t}}+b_{3} R_{F T S E_{t}}+\epsilon_{t} \\
\text { where } \epsilon_{t} \mid \omega_{t-1} \sim N\left(0, h_{t}\right) \\
\log \left(h_{t}\right)=\omega+\alpha\left[\left|\frac{\epsilon_{t-j}}{\sqrt{h_{t-1}}}-\sqrt{\frac{2}{\pi}}\right|\right]+\beta \log \left(h_{t-1}\right)+\delta \frac{\epsilon_{t-1}}{\sqrt{h_{t-1}}}+\gamma D_{C F D_{t}}
\end{gathered}
$$

where $h_{t}$ is known at the beginning of time t. $\Omega_{t-1}$ is the information set at the end of time period t- 1 . This makes the leverage effect exponential instead of quadratic and therefore, estimates of the conditional variance are guaranteed to be non-negative. $R_{t}$ in equation one refers to the Australian index itself and $R_{t-1}$ is the one day lag. The EGARCH model allows for the testing of asymmetries, which is picked up in the $\beta$ term. Similarly to the GARCH model, $R_{\text {Nikkei }_{t}}$ represents the daily return on the NIKKEI 225 and $R_{F T S E_{t}}$ represents the daily return on the FTSE 100. These variables are included in the mean equation to mitigate the EGARCH model against international effects. The EGARCH(1,1) model for the Australian equity-specific analysis includes the Australian index (ASX 200) as an inclusive variable in the mean equation. The structure of the model changes to:

$$
\begin{gathered}
R_{t}=b_{0}+b_{1} R_{t-1}+b_{2} R_{A S X_{t}}+b_{3} R_{\text {Nikkei }_{t}}+b_{4} R_{F T S E_{t}}+\epsilon_{t} \\
\text { where } \epsilon_{t} \mid \omega_{t-1} \sim N\left(0, h_{t}\right) \\
\log \left(h_{t}\right)=\omega+\alpha\left[\left|\frac{\epsilon_{t-j}}{\sqrt{h_{t-1}}}-\sqrt{\frac{2}{\pi}}\right|\right]+\beta \log \left(h_{t-1}\right)+\delta \frac{\epsilon_{t-1}}{\sqrt{h_{t-1}}}+\gamma D_{C F D_{t}}
\end{gathered}
$$

where $R_{t}$ is represents the daily return of the individual equity, $R_{t-1}$ represents the lagged one day before return and $R_{A S X_{t}}$ represents the daily return of the ASX 200 index. $D_{C F D_{t}}$ is included in the variance equation of both equation one and two as a representation of the dummy variable included in the EGARCH models denoting the arrival of CFDs. This variable takes a value of zero prior to the arrival of CFDs and one thereafter. When $\beta=0$, the model is symmetric, but when $\beta<0$, then positive shocks generate less volatility than negative shocks. The model captures the asymmetric features of the dataset, which occurs when an unexpected drop in price due to bad news increases volatility more than an unexpected increase in price because of good news of a similar magnitude. At the equity-specific level, the models are repeated to obtain volatility estimates based on the individual equity at the time of CFD segregation. The EGARCH model is found to be the most optimal methodology to investigate volatility changes between periods. The inclusion of the international exchanges to adapt the model for 'international effects' is also found to be beneficial when attempting to segregate financial crises from that of non-crisis equity behaviour.

methodology, therefore enabling the estimated coefficients to be captured, insulated from the effects of international crises as much as possible.

${ }^{9}$ An intercept and a deterministic trend were included in the Augmented Dickey Fuller (ADF) and Phillips Perron (PP) models. The trend was included to capture the reduction in average volatility that took place during the period prior to the inclusion of CFDs. The ADF model tests whether the equity series contain a unit root in order to correct for serial correlation. PP tests employ a non-parametric estimator of the variance-covariance matrix with $\mathrm{d}$ truncation lags. The models test down by sequentially removing the last lag until a significant lag is reached giving the order of augmentation for the ADF test that minimised the Akaike information criterion. The results indicated rejected of the null-unit root hypotheses at a minimum of the 5 per cent level of significance. $\operatorname{EGARCH}(1,1)$ was selected as the most suitable model to test the hypotheses established in this paper. 


\section{Results}

Table three provides results based on the percentage of CFD volumes traded on the ASX CFD exchange as a proportion of the volumes traded on the standard ASX exchange immediately after the ring-fencing of CFDs in November 2007. The final observation in the sample is March $27^{\text {th }} 2010$, therefore nine quarters of data are available. The same data is available at the equity specific level as found in Appendix A.

We can see from table three that since the birth of the ASX CFD exchange, $8.83 \%$ of the total exchange volume has been traded in CFDs. This also shows a notable increasing trend with a peak of $14.2 \%$ in Q4 2009. Investigating equity-specific data, we find that there are companies that experience over $50 \%$ of CFD to exchange volumes. Though United Kingdom and Irish CFD estimates reached twenty to fifty per cent around the same period as CFD ring-fencing in Australia (FSA, 2007), the estimates provided in Appendix A show that Australian CFD trading was significantly lower, ranging between eight and fourteen percent. Some reasons for this lower than expected estimate would be the relative youth of the ASX CFD exchange, as spreads were found to be still relatively wide and liquidity was found to be lower than that expected as investors waited to see if the new exchange was a feasible proposition.

Table 3. Percentage CFD volume as a proportion of total volume (as a percentage $(\%)$ ) immediately after CFD ring-fencing

\begin{tabular}{|c|c|}
\hline Quarter & Percentage (\%) \\
\hline Q1 2008 & 5.08 \\
\hline Q2 2008 & 7.13 \\
\hline Q3 2008 & 5.92 \\
\hline Q4 2008 & 3.61 \\
\hline Q1 2009 & 8.66 \\
\hline Q2 2009 & 9.52 \\
\hline Q3 2009 2009 & 12.39 \\
\hline Q1 2010 & 14.21 \\
\hline
\end{tabular}

Note: The above statistics are associated with the calculations of CFD volume traded for equities on the ASX exchange are divided by the alternative non-CFD volumes. The percentage (\%) statistics represents the percentage of total exchange volume traded as CFDs.

The EGARCH $(1,1)$ analysis at the index level in table four finds that volatility decreased $0.78 \%$ after the introduction of CFDs. Of further interest is the change in volatility after the ringfencing of CFDs to their own separate exchange. In the period after the division of the ASX and ASX CFD exchange, volatility increased $3.55 \%$. This result holds after mitigation international effects through the use of the Nikkei 225 and FTSE 100 indices in the mean equation. The results for the inclusion of CFDs are significant at the $10 \%$ level, while the results based on the withdrawal of CFDs are significant at the $1 \%$ level.

Table 4. EGARCH $(1,1)$ results for the ASX exchange at the introduction and ring-fencing of CFDs

\begin{tabular}{|c|c|c|c|c|c|c|c|c|c|}
\hline Timeframe & $\boldsymbol{b}_{\mathbf{0}}$ & $\boldsymbol{b}_{\mathbf{1}}$ & $\boldsymbol{b}_{\mathbf{2}}$ & $\boldsymbol{b}_{\mathbf{3}}$ & $\boldsymbol{\omega}$ & $\boldsymbol{\alpha}$ & $\boldsymbol{\delta}$ & $\boldsymbol{\beta}$ & $\boldsymbol{\gamma}(\mathbf{t}-\mathbf{s t a t})$ \\
\hline $\begin{array}{c}\text { CFDs Intro } \\
\text { Obs:2156 }\end{array}$ & $\begin{array}{c}0.0251 \\
(2.19)^{*}\end{array}$ & $\begin{array}{c}-0.0771 \\
(-4.61)^{* * *}\end{array}$ & $\begin{array}{c}0.2073 \\
(24.36)^{* * *}\end{array}$ & $\begin{array}{c}0.30907 \\
(19.52)^{* * *}\end{array}$ & $\begin{array}{c}0.01612 \\
(3.42)^{* * *}\end{array}$ & $\begin{array}{c}-0.0747 \\
(-6.94)^{* * *}\end{array}$ & $\begin{array}{c}0.11351 \\
(7.66)^{* * *}\end{array}$ & $\begin{array}{c}0.97499 \\
(7.66)^{* * *}\end{array}$ & $\begin{array}{c}\mathbf{- 0 . 0 0 7 8 3} \\
(-2.11)^{*}\end{array}$ \\
\hline $\begin{array}{c}\text { CFDs Exit } \\
\text { Obs:2079 }\end{array}$ & $\begin{array}{c}0.02258 \\
(1.68)\end{array}$ & $\begin{array}{c}-0.1082 \\
(-6.20)^{* * *}\end{array}$ & $\begin{array}{c}0.29381 \\
(27.38)^{* * *}\end{array}$ & $\begin{array}{c}0.3860 \\
(17.22)^{* * *}\end{array}$ & $\begin{array}{c}0.0048 \\
(0.10)\end{array}$ & $\begin{array}{c}-0.094 \\
(-7.18)^{* * *}\end{array}$ & $\begin{array}{c}0.128 \\
(7.18)^{* * *}\end{array}$ & $\begin{array}{c}0.96566 \\
(143.2)^{* * *}\end{array}$ & $\mathbf{+ 0 . 0 3 5 5 8}$ \\
$(\mathbf{3 . 9 7}) * * *$
\end{tabular}

Note: The above table shows the associated EGARCH(1,1) coefficients in the period before CFD segregation to the ASX CFD exchange. T-statistics are in parentheses where $* * * p<0.01, * * p<0.05$ and $* \mathrm{p}<0.10$. The results in table four are based on equation one in section four.

These findings offer significant evidence that the initial inclusion of CFDs on the ASX exchange was associated with a reduction in volatility and there is evidence that this finding reversed after the ring-fencing. Volatility increased by $3.55 \%$ after the segregation of CFDs, with this figure 
adjusted for international crises effects. With CFDs accounting for eight to fourteen per cent of total exchange liquidity, this reduction may have caused volatility increases through a simultaneous decrease in liquidity. These findings may also be consistent with the hypothesis proposed in Ireland by the Irish Banking Commission's investigation into the collapse of Anglo Irish Bank. They found that an 'overhang' artificially manipulated market volatility through direct impacts on the bid and ask price of the traded equity. The results after the segregation of CFDs are also valuable, as an increase in volatility could also be associated with the relief of any CFD influenced 'overhangs' present in the market.

Table 5. EGARCH $(1,1)$ volatility results after the ring-fencing of CFDs for individual Australian equities

\begin{tabular}{|c|c|}
\hline Company & $\gamma$ coefficient \\
\hline Alumina & $0.121^{* *}$ \\
\hline Amcor & $0.157 * * *$ \\
\hline AMP & $-0.017 * *$ \\
\hline ANZ & $0.919 *$ \\
\hline AXA & $2.447^{*}$ \\
\hline BHP Billiton & 0.011 \\
\hline Boral & $0.071 * *$ \\
\hline Coca Cola & $-0.016^{* * *}$ \\
\hline CSR & $-0.039 * * *$ \\
\hline $\mathrm{CBA}$ & $0.416^{* *}$ \\
\hline CSL & 0.042 \\
\hline Fosters & $0.932 * * *$ \\
\hline IAG & $0.719 * * *$ \\
\hline Fairfax & $2.583 * * *$ \\
\hline Lihir Gold & 0.035 \\
\hline Newcrest & 0.199 \\
\hline News Corp & $1.396^{*}$ \\
\hline Origin & $0.487 * * *$ \\
\hline Oil Search & $1.223 *$ \\
\hline Orica & $0.196 * * *$ \\
\hline One Steel & 0.056 \\
\hline QBE & $2.285^{*}$ \\
\hline Qantas & $2.022 *$ \\
\hline Rio Tinto & 0.018 \\
\hline Santos & $0.400 * *$ \\
\hline Suncorp & $1.346^{*}$ \\
\hline Tabcorp & $1.324 *$ \\
\hline Toll Holdings & $0.592 *$ \\
\hline Transurban & $0.183^{*}$ \\
\hline Telecom NZ & $-0.009 * * *$ \\
\hline Westpac & $1.328^{*}$ \\
\hline Westfield & $0.106^{* * *}$ \\
\hline Woolworth & $1.197^{*}$ \\
\hline Woodside & $0.158 * * *$ \\
\hline Wesfarmers & $0.128 * *$ \\
\hline
\end{tabular}

Note: The above table represents the estimated $\gamma$ coefficients for each investigated Australian company traded on the ASX CFD exchange using the discussed EGARCH $(1,1)$ methodology to investigate changes in volatility dynamics after CFD introduction. The robust standard errors for each of the $\gamma$ coefficients are marked in parentheses, where ${ }^{* * *} \mathrm{p}<0.01,{ }^{* *} \mathrm{p}<0.05$ and ${ }^{*} \mathrm{p}<0.10$. The resulting coefficients are designed to be portrayed as the percentage change in volatility. The above results focus specifically on the period after the ring-fencing of CFDs in November 2007. Insufficient data around the period of the introduction of CFDs resulted in EGARCH methodology failure. The table containing the full $\operatorname{EGARCH}(1,1)$ results for table five can be found in the Appendix B. 
The ASX exchange consists of over five hundred equities, but the ASX CFD exchange only includes the most liquid equities that are traded. On the ASX CFD exchange, there are fifty equities included. This paper includes thirty-five of the fifty due to data limitations and illiquidity that lead to the EGARCH models failing to provide significant results. Analysis of the period at the time of the introduction of CFDs in Australia in late-2002 at the equity-specific level proved to be implausible, as data only became available for Australian equities between late 2001 and early 2002. This lack of data resulted in failure of the EGARCH(1,1) methodology. But results could be inferred from the period of ring-fencing CFDs in 2007. Similarly to the ASX EGARCH methodology, the models are repeated on the individual equities to obtain volatility estimates through the $\gamma$ coefficient. The resulting $\gamma$ coefficient is designed in this manner to offer the percentage change in volatility between the two periods. Only the $\gamma$ coefficients are included in table five, whereas the complete list of coefficients calculated by the EGARCH $(1,1)$ methodology are found in Appendix B.

In table five, thirty-one of the thirty-five equities demonstrated increased volatility after the creation of the ASX CFD exchange. The largest volatility increase occurred in Fairfax equity (258.3 percent), whereas the largest decrease occurred in CSR equity (-3.9 per cent). These results again indicate that the segregation of CFD trading to the ASX CFD exchange mostly resulted in an increase in equity-specific volatility.

The ASX CFD exchange was created to withdraw any potential effects that CFDs may have on the underlying ASX exchange. Its creation also aimed at providing additional benefits through improved transparency, increased market independence and a reduction in counterparty risk. The results of the index-EGARCH $(1,1)$ methodology show that there was a reduction in Australian equity volatility after the arrival of CFDs, whereas there was a large increase in volatility after the segregation of CFDs to a separate exchange. At the equity-specific level, there was also a large increase in volatility in thirty-one of the thirty-five included equities after CFD segregation. These results provide evidence that cannot reject the presence of 'overhangs' in Australian equity markets. The results are consistent with Irish empirical evidence as reported by The Irish Banking Commission (2011) and Corbet and Twomey (2013). The segregation of CFDs appears to have provided benefits to the standard equity market in Australia through the alleviation of CFD 'overhangs'. In terms of a cost benefit analysis, though the benefits of CFD transparency are significant, there have been some negative issues. There has been significant negative commentary based on the higher costs of operating the exchange, with these costs being passed to the investor due to higher broker's administration costs to comply with exchange clearing requirements. There are also limited products available due to the lack of liquidity on a majority of ASX equities. Mispricing has also found to be significant between the underlying equity and the CFD provided on the segregated exchange. In some instances, while the underlying instruments are liquid and heavily traded with a tight spread, the ASX CFD based on that instrument may have little or no liquidity and a wider spread. But as the presence of 'overhangs' cannot be rejected and the $\operatorname{EGARCH}(1,1)$ volatility estimates provide evidence supporting their influence, issues associated with the ASX CFD exchange may be outweighed by benefits on the standard ASX index as the withdrawal of CFDs have promoted increased market transparency and functionality.

\section{Conclusions}

This paper presents an analysis of the effects of CFDs on Australian equity markets since their introduction in late 2002 and subsequent withdrawal in late 2007. An EGARCH analysis is used to uncover volatility changes in the periods before and after the introduction of CFDs in Australia. In terms of liquidity effects, the volumes of CFDs traded are found to be in line with numerous international estimates. It is found that eight to fourteen per cent of total exchange activity is CFD related between 2008 and 2010, with some individual equities exposed to CFD trading volumes above fifty per cent in particular quarters. The EGARCH analysis indicates that the ASX was subjected to a decrease in volatility after the introduction of CFDs and an increase in volatility after the creation of the ASX CFD exchange. At the equity-specific level, thirty-one of the thirty-five equities investigated showed a similar increase in volatility after the segregation of CFDs. These results offer evidence supporting the presence of 'overhangs' stemming from market orders used in the hedging practices of CFD brokers. The volatility increase found after CFD segregation may in fact be associated with the alleviation of these 'overhangs' with the markets returning to a non-CFD influenced trading state. 
In terms of policymaking, a lack of transparency found in the Australian stock market resulted in CFDs being ring-fenced to their own separate exchange in 2007. Other international CFDinfluenced anomalies include the resulting positions built in Anglo Irish Bank and the trading anomaly associated with VW in 2008. These anomalies have been associated with 'overhangs' which have been found to hinder standard market functionality. The findings of this paper cannot separate CFDs from a potential negative role in the Australian equity market. It appears that the decision to ring-fence CFDs may have been correct and does appear to have alleviated any price restricting characteristics that the product provides. Although there have been some negative effects associated with the creation of the exchange, such as inefficient liquidity and substantial cost, this paper finds that standard equity markets presented increased volatility after the segregation of CFDs, indicating that markets may have been alleviated of negative effects stemming from CFD 'overhangs'.

To gain a role as a standard international investment product, CFDs have to become more transparent. This is vital to their long-term success. Sources of market data should be obliged to segregate leveraged positions on Australian equities, along with all CFD stop losses and limit orders. Options and futures products have separate exchanges, even though their products are fundamentally established on the cash market, which provides full transparency so all effects can be viewed by informed traders. The overall findings of this paper indicate that CFDs should follow this template.

\section{References}

Antoniou, A., Holmes, P. 1995. Futures trading, information and spot price volatility: evidence for the FTSE-100 stock index futures contract using GARCH, Journal of Banking and Finance, $19,117-29$.

Antoniou, A, Holmes, P., Priestley, R. 1998. The effects of stock index futures trading on stock index volatility: An analysis of the asymmetric response of volatility to news? The Journal of Futures Markets, 18(2), 151-166.

Baillie, R.T., Bollerslev, T. 1991. Intra-Day and Inter-Market Volatility in Foreign Exchange Rates, Review of Economic Studies, 58(3), 565-585.

Bessembinder, H. and Seguin, P.J. 1993. Price volatility, trading volume and market depth: Evidence from Futures Markets, Journal of Financial Economics, 47, pp.339-355.

Bloomfield, R., O'Hara, M., Saar, G. 2009. 'How noise trading affects markets: An experimental analysis', Review of Financial Studies, 22(6), 2275-2302.

Bologna, P., Cavallo, L. 2002. Does the introduction of stock index futures effectively reduce stock market volatility? Is the futures effect immediate? Evidence from the Italian Stock Exchange using GARCH'. Applied Financial Economics, 12, 183-192

Brown, G.W. 1999, Volatility, Sentiment and Noise Traders, Financial Analysts Journal, 55(2), 82-90.

Brown, C., Dark, J., Davis, K. 2009. Exchange Traded Contracts for Difference: Design, pricing and effects, Working Paper Series, University of Melbourne, Department of Finance, June.

Central Bank of Ireland, 2011. Central Bank inspection identifies compliance concerns in Contracts for Difference and Financial Spread Betting Firms, Information Release, $16^{\text {th }}$ of June, 2011.

Chathrath, A., Ramchander, S., Song, F. 1995. Does option trading lead to greater cash market volatility? Journal of Futures Markets, 15(7), 785-803.

Chung, J.M., Choe, H., Kho, B.C. 2009. 'The impact of day-trading on volatility and liquidity', AsiaPacific Journal of Financial Studies, 38(2), 237-275.

Commission of investigation into the banking sector in Ireland, 2011. Misjudging risk: Causes of the systemic banking crisis in Ireland, Report of the Commission of Investigation into the Banking Sector in Ireland, pp.1-156.

Corbet, S., Twomey, C. 2013. How have Contracts for Difference affected Irish equity market volatility? National University of Ireland Galway, Working Paper, November.

Deloitte, 2010. Tax treatment of CFDs', Public report on the tax situation associated with CFDs in Australia, released $5^{\text {th }}$ November 2010, 1-26.

Drimbetas, E., Sariannidis, N., Porfiris, N. 2007. The effect of derivatives trading on the volatility of the underlying asset: evidence from the Greek stock market. Applied Financial Economics, 17(2), 139-148. 
Edwards, F.R. 1988. Does Futures Trading Increase Stock Market Volatility? Financial Analysts Journal, 44(1), 63-69.

European Securities Market Expert Group (ESME), 2009. Views on the transparency of holdings of cash settled derivatives, Directives published to The European Commission, November.

Financial Services Authority (FSA) of the United Kingdom, 2007. 'Disclosure of Contracts for Difference', Consultation and draft handbook text, FSA-CP07-20, 2007, November.

Gulen, H., Mayhew, S. 2000. Stock index futures trading and volatility in international equity markets, The Journal of Futures Markets, 20(7), 661-685.

Kumar, R., Atulya, S., Kuldeep, S. 1995, The impact of the listing of index options on the underlying stocks, Pacific-Basin Finance Journal, 3, 303-317.

Nelson, D.B. 1991. 'Conditional heteroskedasticity in asset returns: a new approach'. Econometrica, 59(2), 347-370.

Pok, W.C., Poshakwale, S. 2004. The impact of the introduction of futures contracts on spot market volatility: the case of the Kuala Lumpur stock exchange, Applied Financial Economics, 14, 14354.

Schwert, G.W. 2011. Stock Volatility during the Recent Financial Crisis, European Financial Management, 17(5), 789-805. 
Quantifying the Effects of the Inclusion and Segregation of Contracts for Difference in Australian Equity Markets

Appendix A: ASX CFD volumes as a percentage of total market volumes (\%) immediately after CFD ring-fencing

\begin{tabular}{|c|c|c|c|c|c|c|c|c|c|c|}
\hline Equity & Q1 2008 & Q2 2008 & Q3 2008 & Q4 2008 & Q1 2009 & Q2 2009 & Q3 2009 & Q4 2009 & Q1 2010 & Average \\
\hline Amcor & 5.14 & 4.11 & 1.57 & 0.14 & 14.89 & 11.67 & 7.55 & 7.87 & 4.22 & 6.35 \\
\hline Alumina & 3.58 & 2.59 & 1.67 & 1.40 & 1.24 & 1.00 & 5.07 & 3.23 & 7.20 & 2.99 \\
\hline AMP & 1.62 & 1.56 & 2.52 & 1.22 & 6.01 & 9.26 & 6.80 & 7.05 & 6.50 & 4.72 \\
\hline ANZ & 6.76 & 10.02 & 5.56 & 2.54 & 5.67 & 6.91 & 9.96 & 10.06 & 7.73 & 7.24 \\
\hline$\overline{A X A}$ & 7.66 & 14.69 & 8.35 & 3.11 & 2.45 & 2.49 & 3.15 & 4.16 & 4.81 & 5.65 \\
\hline BHP Billiton & 8.71 & 12.86 & 9.13 & 5.64 & 7.28 & 9.11 & 12.96 & 11.74 & 9.75 & 9.68 \\
\hline Boral & 3.54 & 3.67 & 1.45 & 2.38 & 5.17 & 11.33 & 20.31 & 29.09 & 42.21 & 13.23 \\
\hline Coca Cola & 3.46 & 4.07 & 6.61 & 5.17 & 7.51 & 7.63 & 7.62 & 10.17 & 16.25 & 7.61 \\
\hline CSR & 5.75 & 5.01 & 3.48 & 0.89 & 2.37 & 7.50 & 22.96 & 16.40 & 2.47 & 7.42 \\
\hline $\mathrm{CBA}$ & 1.23 & 2.19 & 0.60 & 0.72 & 15.04 & 5.66 & 9.36 & 4.59 & 4.11 & 4.83 \\
\hline CSL & 1.10 & 2.65 & 15.04 & 1.58 & 16.36 & 5.27 & 11.79 & 15.23 & 27.06 & 10.67 \\
\hline Fosters & 17.58 & 8.88 & 6.65 & 8.21 & 6.85 & 19.25 & 20.30 & 27.96 & 11.05 & 14.08 \\
\hline IAG & 0.63 & 0.65 & 1.07 & 0.95 & 2.64 & 2.61 & 4.02 & 3.44 & 4.11 & 2.23 \\
\hline Fairfax & 1.20 & 4.55 & 1.72 & 1.56 & 0.70 & 11.38 & 2.68 & 4.66 & 2.43 & 3.43 \\
\hline Lihir Gold & 0.80 & 0.51 & 1.82 & 0.16 & 2.09 & 15.00 & 0.86 & 199 & 2.36 & 2.84 \\
\hline MAB & 3.07 & 0.99 & 0.66 & 0.64 & 1.09 & 1.20 & 3.81 & 13.22 & 4.56 & 3.24 \\
\hline Newcrest & 0.70 & 3.28 & 2.29 & 2.92 & 12.58 & 12.40 & 7.19 & 7.77 & 18.27 & 7.48 \\
\hline News Corp & 7.39 & 27.47 & 9.63 & 14.38 & 13.30 & 12.22 & 44.17 & 72.85 & 55.36 & 28.53 \\
\hline Origin & 2.21 & 1.39 & 10.80 & 9.92 & 6.75 & 14.23 & 19.01 & 38.30 & 22.76 & 13.93 \\
\hline Oil Search & 4.20 & 1.34 & 1.44 & 1.35 & 11.96 & 43.64 & 22.97 & 23.27 & 3.93 & 12.67 \\
\hline Orica & 7.68 & 13.01 & 22.78 & 5.79 & 72.55 & 19.18 & 67.49 & 28.59 & 37.16 & 30.47 \\
\hline Onesteel & 7.19 & 17.40 & 22.36 & 6.16 & 7.25 & 12.03 & 16.44 & 20.87 & 10.51 & 13.35 \\
\hline Paladin & 3.58 & 4.08 & 3.10 & 1.57 & 6.15 & 3.17 & 6.29 & 11.67 & 6.52 & 5.12 \\
\hline QBE Insur. & 1.40 & 3.49 & 2.56 & 3.88 & 0.94 & 0.86 & 0.87 & 2.14 & 2.23 & 2.04 \\
\hline Quantas & 3.63 & 3.38 & 3.90 & 1.37 & 0.86 & 1.80 & 4.97 & 2.98 & 1.20 & 2.67 \\
\hline Rio Tinto & 3.89 & 39.30 & 20.46 & 4.27 & 3.93 & 8.31 & 12.46 & 19.67 & 15.87 & 14.24 \\
\hline Santos & 0.90 & 1.93 & 2.18 & 0.81 & 3.19 & 3.65 & 5.22 & 4.80 & 3.93 & 2.95 \\
\hline Suncorp & 17.67 & 10.38 & 2.76 & 0.78 & 3.86 & 17.47 & 7.69 & 13.07 & 16.31 & 9.99 \\
\hline Tabcorp & 9.12 & 17.43 & 19.75 & 28.08 & 3.64 & 11.64 & 22.86 & 24.60 & 38.16 & 19.47 \\
\hline Toll Holdings & 6.09 & 5.65 & 8.54 & 2.37 & 13.43 & 28.57 & 30.44 & 14.61 & 8.26 & 13.10 \\
\hline Transurban & 0.99 & 2.57 & 3.60 & 6.44 & 11.30 & 19.57 & 22.30 & 14.07 & 23.12 & 11.55 \\
\hline Telecom Corp. & 1.84 & 1.77 & 1.68 & 5.31 & 8.05 & 3.79 & 11.78 & 20.88 & 15.09 & 7.79 \\
\hline Westpac & 2.24 & 4.03 & 3.17 & 0.69 & 2.35 & 1.65 & 4.73 & 9.76 & 7.60 & 4.02 \\
\hline Westfield & 2.46 & 3.39 & 3.05 & 1.77 & 1.47 & 1.09 & 2.21 & 4.47 & 2.93 & 2.53 \\
\hline Woolworth & 2.34 & 8.53 & 2.44 & 1.14 & 11.61 & 0.58 & 10.62 & 2.18 & 3.57 & 4.77 \\
\hline Woodside & 30.71 & 14.58 & 8.49 & 1.27 & 34.73 & 16.17 & 13.56 & 7.17 & 15.48 & 15.79 \\
\hline Wesfarmers & 3.82 & 6.95 & 1.62 & 0.38 & 1.60 & 0.47 & 7.24 & 23.51 & 5.52 & 5.67 \\
\hline
\end{tabular}

Note: The data was collected from the Australian Securities exchange at www.asx.au. The results are calculated as the deleveraged representation of a full margined trading position specific to the company in the stated time period. The result is then divided by the associated spot market trading volumes to offer a representation of approximate CFD exposures on the Australian Securities Exchange (ASX). 
Appendix B: EGARCH(1,1) volatility results after the ring-fencing of CFDs for individual Australian equities

\begin{tabular}{|c|c|c|c|c|c|c|c|c|c|}
\hline Equity & $\boldsymbol{\beta}_{0}$ & $\beta_{1}$ & $\beta_{2}$ & $\beta_{3}$ & $\boldsymbol{\beta}_{4}$ & $\alpha$ & 9 & $\boldsymbol{\beta}$ & $\gamma$ \\
\hline Alumina & 0.173 & -0.058 & $1.213 * * *$ & $0.479 *$ & $0.611 * *$ & 0.043 & $0.029 *$ & $0.939 * *$ & $0.121 * *$ \\
\hline Amcor & 0.174 & $-0.073 * * *$ & $0.277 * * *$ & $0.387 *$ & 0.588 & -0.058 & $0.025^{*}$ & $0.886^{* * *}$ & $0.157 * * *$ \\
\hline AMP & 0.036 & $-0.064 * * *$ & $0.657 * * *$ & $0.319^{*}$ & $0.194 * *$ & $0.102^{*}$ & $0.015^{*}$ & $0.945 * *$ & $-0.017 * *$ \\
\hline ANZ & 0.082 & $-0.094 * *$ & $0.777 * * *$ & $0.255^{*}$ & $0.398^{* * *}$ & $0.011^{* *}$ & $0.043^{* *}$ & $0.863^{*}$ & 0.919* \\
\hline AXA & 0.171 & $-0.099 *$ & $0.637 * * *$ & $0.533^{*}$ & $0.264^{*}$ & $0.029^{*}$ & 0.076 & $0.712 *$ & $2.447 *$ \\
\hline BHP Billiton & $0.332^{* *}$ & $-0.158^{*}$ & $1.007 * * *$ & $0.266^{*}$ & $0.255^{*}$ & 0.002 & $0.022 *$ & $0.970^{*}$ & 0.011 \\
\hline Boral & 0.001 & -0.026 & $0.832 * * *$ & $0.319^{* *}$ & $0.815^{* *}$ & $0.088 * *$ & 0.064 & $0.929^{*}$ & $0.071 * *$ \\
\hline Coca Cola & $0.242 * *$ & $-0.144 *$ & $0.282 * * *$ & $0.071^{*}$ & $0.915^{*}$ & $0.051^{* *}$ & $0.101 * * *$ & $0.981^{* * *}$ & $-0.016 * * *$ \\
\hline CSR & 0.087 & $-0.165^{*}$ & $1.346^{* * *}$ & $0.245^{* *}$ & 0.621 & 0.006 & $0.094 * *$ & $0.901^{*}$ & $-0.039 * * *$ \\
\hline CBA & 0.096 & $-0.063^{* * *}$ & $0.524 * * *$ & $0.263^{*}$ & $0.267 * * *$ & 0.096 & $0.224 *$ & $0.763^{*}$ & $0.416^{* *}$ \\
\hline CSL & $0.442 * *$ & -0.055 & $0.248 * * *$ & $0.405^{*}$ & $0.134 *$ & $0.213^{*}$ & 0.041 & $0.686^{*}$ & 0.042 \\
\hline Fosters & 0.042 & $-0.129^{*}$ & $0.446^{* *}$ & $0.116^{* * *}$ & 0.433 & $0.092 *$ & $0.141^{* *}$ & $0.757 *$ & $0.932 * * *$ \\
\hline IAG & 0.076 & -0.032 & $0.376^{* * *}$ & $0.451^{* *}$ & $0.378^{* * *}$ & $0.095 * *$ & $0.186^{* *}$ & $0.577^{*}$ & $0.719 * * *$ \\
\hline Fairfax & 0.012 & $-0.073 * *$ & $0.651 * * *$ & $0.244^{*}$ & $0.133^{*}$ & $0.034 * * *$ & $0.037 * * *$ & $0.947 * *$ & $2.583 * * *$ \\
\hline Lihir Gold & $0.361 * * *$ & 0.032 & $0.618^{* * *}$ & 0.058 & 0.613 & $0.045^{*}$ & $0.022 * *$ & $0.923 * * *$ & 0.035 \\
\hline Newcrest & $0.099^{*}$ & $0.453 *$ & $0.065^{* * *}$ & 0.038 & $0.248 * *$ & 0.044 & $0.159^{*}$ & $0.832 *$ & 0.199 \\
\hline News Corp. & $0.417 * *$ & -0.041 & $0.371^{* *}$ & $0.376^{* *}$ & $0.641^{*}$ & 0.125 & $0.015^{* *}$ & $0.974 * * *$ & $1.396^{*}$ \\
\hline Origin & $0.724 *$ & $-0.155^{*}$ & $0.521 * *$ & $0.848^{*}$ & $0.789^{*}$ & $0.016^{* *}$ & 0.075 & $0.893 * * *$ & $0.487 * * *$ \\
\hline Oil Search & 0.191 & $-0.145^{*}$ & $0.707 * * *$ & $0.407^{* *}$ & $0.134 *$ & 0.082 & $0.109 * *$ & $0.873 * *$ & $1.223^{*}$ \\
\hline Orica & 0.231 & 0.037 & $0.713 * * *$ & $0.388^{*}$ & $0.967 *$ & 0.018 & $0.139 * *$ & $0.941^{*}$ & $0.196 * * *$ \\
\hline One Steel & $0.353 * *$ & $-0.116^{* *}$ & $0.726^{* * *}$ & $0.094^{* *}$ & $0.559^{*}$ & 0.052 & 0.052 & $0.751 * * *$ & 0.056 \\
\hline QBE & 0.009 & $-0.098 * *$ & $0.442 * * *$ & $0.451^{* *}$ & 0.294 & $0.038^{* * *}$ & $0.056^{* * *}$ & $0.937^{*}$ & $2.285^{*}$ \\
\hline Rio Tinto & $0.305 * * *$ & -0.055 & $0.752 * *$ & $0.205^{*}$ & $0.751^{*}$ & 0.017 & $0.017 *$ & $0.981 * * *$ & $2.022 *$ \\
\hline Santos & 0.202 & $-0.089 * *$ & $0.619 * * *$ & $0.091 *$ & $0.153 *$ & $0.018 * * *$ & $0.035^{* *}$ & $0.895^{*}$ & 0.018 \\
\hline Suncorp & 0.042 & $-0.112 * *$ & $0.705 * * *$ & $0.161^{* *}$ & $0.123 *$ & $0.100 * * *$ & $0.021^{*}$ & $0.804 *$ & $1.346^{*}$ \\
\hline Tabcorp & 0.004 & $-0.088 * *$ & $0.911 * * *$ & $0.286^{*}$ & $0.412 *$ & $0.179^{*}$ & $0.037 * * *$ & $0.849^{*}$ & $1.324 *$ \\
\hline Toll Holdings & 0.071 & 0.012 & $0.748 * *$ & $0.748^{*}$ & $0.951^{* *}$ & 0.091 & $0.015 * * *$ & $0.930^{* *}$ & $0.592 *$ \\
\hline Transurban & 0.142 & $-0.096 * * *$ & $0.252 * * *$ & $0.154^{* *}$ & $0.229 * *$ & 0.007 & $0.096^{*}$ & $0.893^{*}$ & $0.183^{*}$ \\
\hline Tel. NZ & $0.192 * * *$ & $-0.118^{*}$ & $0.621^{* * *}$ & $0.218^{*}$ & 0.541 & 0.126 & 0.021 & $0.975^{*}$ & $-0.009 * * *$ \\
\hline Westpac & 0.062 & $-0.121 *$ & $0.621 * * *$ & $0.176^{*}$ & 0.315 & 0.235 & 0.035 & 0.934 & $1.328^{*}$ \\
\hline Westfield & 0.014 & $-0.187 * *$ & $0.436^{* * *}$ & $0.146^{*}$ & $0.210^{*}$ & 0.025 & $0.048^{* *}$ & $0.927 * *$ & $0.106^{* * *}$ \\
\hline Woolworth & $0.225 * *$ & $-0.162 *$ & $0.365^{* *}$ & $0.187^{* *}$ & $0.248 * * *$ & 0.045 & 0.001 & $0.769 * * *$ & $1.197^{*}$ \\
\hline Woodside & $0.274 * * *$ & -0.043 & $0.826^{* * *}$ & $0.298^{*}$ & $0381 *$ & 0.052 & $0.189 *$ & $0.777^{*}$ & $0.158 * * *$ \\
\hline Wesfarmers & $0.185^{*}$ & $-0.075 * * *$ & $0.602 * *$ & $0.277^{*}$ & $0.348 * *$ & 0.041 & $0.081 *$ & $0.907 * * *$ & $0.128 * *$ \\
\hline
\end{tabular}

Note: T-statistics are in parentheses where ${ }^{* * *} \mathrm{p}<0.01,{ }^{* *} \mathrm{p}<0.05$ and ${ }^{*} \mathrm{p}<0.10 . \gamma$ represents the EGARCH$(1,1)$ calculated volatility change after CFD segregation to the separate ASX CFD exchange for the specific Australian equities traded. 